\title{
Retrospective Long-Term Comparison of Naturopathic Fasting Therapy and Weight Reduction Diet in Overweight Patients
}

\author{
André-Michael Beer, ${ }^{1}$ Lena Elisabeth Ismar, ${ }^{2}$ Dominik Karl Wessely, ${ }^{2}$ Tanja Pötschke, \\ Beate Weidner, ${ }^{1}$ and Karl Rüdiger Wiebelitz ${ }^{3}$ \\ ${ }^{1}$ Department of Naturopathy, Blankenstein Hospital, Im Vogelsang 5-11, 45527 Hattingen, Germany \\ ${ }^{2}$ Department of Neurology, St. Johannes-Hospital, Springufer 7, 59755 Arnsberg, Germany \\ ${ }^{3}$ Clinic for Children and Adolescents, Prignitz Hospital, Dobberzinerstraße 112, 19348 Perleberg, Germany \\ Correspondence should be addressed to Karl Rüdiger Wiebelitz; ruediger.wiebelitz@gmx.de
}

Received 28 December 2013; Revised 3 May 2014; Accepted 10 June 2014; Published 13 July 2014

Academic Editor: Thomas Ostermann

Copyright (C) 2014 André-Michael Beer et al. This is an open access article distributed under the Creative Commons Attribution License, which permits unrestricted use, distribution, and reproduction in any medium, provided the original work is properly cited.

\begin{abstract}
In a follow-up study overweight and obese patients fasting according to Buchinger (modified) and a control group treated by a weight reduction diet in the context of an inpatient naturopathic complex treatment were compared using a questionnaire developed for a standardized phone interview $6.8 \pm 1.1$ years after inpatient treatment. During the inpatient treatment the fasting patients significantly more body weight, but at the time of the interview significantly more weight was gained again. $10.7 \%$ of the fasting patients and $31.9 \%$ of the control group lowered their weight at least $5 \%$ of their initial weight up to the interview. $42 \%$ of the fasting and $74 \%$ of the control group persistently changed their diet. The control group followed a significantly higher number of trained nutritional aspects. $21 \%$ of the fasting and $40 \%$ of the control group increased their leisure activity permanently. Continued improvement in quality of life was achieved by $16 \%$ of the fasting patients and $28 \%$ of the control group. The fasting therapy, carried out as part of the inpatient naturopathic complex treatment, turned out to be less suitable for the treatment of overweight and obesity compared to standard therapy. One likely determinant is the minor poststationary lifestyle modification.
\end{abstract}

\section{Introduction}

Multiple comorbidities are associated with overweight and obesity: cardiovascular diseases $[1,2]$, type II diabetes mellitus [3], and malignancies [4]. The moderately energyreduced mixed diet (weight reduction diet) is considered as the standard treatment for obesity [5-7]. In view of the increasing prevalence of overweight and obesity fasting therapy, an established method of classical naturopathy [8, 9] appears to be a potential treatment option [10, 11]. Up to now only few studies examined the possible potential of fasting therapy. Therefore, scientific studies are urgently needed on this issue $[12,13]$. While the weight loss during the period of fasting therapy is documented in several studies on different topics [14-16], studies that examine the long-term course of weight are rare. Whether fasting therapy leads to a long-term life style modification in obese patients, coupled with sustained weight reduction, a sustained changed diet and a lasting increase in physical activity and quality of life are not yet known. Likewise the long-term weight gain and lifestyle modification in overweight and obese patients after completion of fasting therapy versus standard weight reduction diet have not been scientifically evaluated. This question is therefore investigated in the present study.

A weight loss of $5 \%$ of the initial weight is generally considered successful and is also the defined treatment goal in the current guidelines for the prevention and treatment of obesity [6]. Therefore the primary outcome measure in this study is the proportion of patients who, after fasting therapy or weight reduction diet, achieved a sustained weight loss of at least $5 \%$ of their initial weight. The potential difference between the patient groups was determined.

Further examination criteria (secondary objectives) were group differences regarding the ongoing absolute weight reduction compared to baseline body weight, the weight loss of more than $2.25 \mathrm{~kg}$ as a further criterion of success, 
the weight development in poststationary continued weight reduction and/or prolonged weight maintenance, the persistent change in diet taking account of the rules of nutrition therapy, the observing of specific inpatient trained nutritional aspects and the relationship between the number of observed aspects of nutrition and weight loss, the ongoing increase in physical activity in the form of basic, leisure and sports activities, and the posthospital quality of life with regard to body weight.

\section{Materials and Methods}

The study was conducted as a single center comparative retrospective follow-up study. We compared both shortand long-term effects of the modified Buchinger fasting therapy [9] with the treatment with weight reduction diet in overweight and obese patients. The modified Buchinger fasting therapy, which includes vegetable stocks and vegetable juices, tea, and water, but no fruit juices or solid foods, was combined with regular defecation and exercise alternating with rest and was followed by a gradual return to solid food over 3 days. The mean duration of fasting therapy was $10.3 \pm 1.8$ days. $87 \%$ of fasting patients received subsequently a weight reduction diet and $13 \%$ a balanced basic diet [9, 17].

Weight reduction diet means a diet with reduced caloric feed charge. Patients receive a well-balanced low-fat and modified fat wholefood basic diet with a daily energetic deficit of $500-800 \mathrm{kcal}$. The food contains $\sim 50 \%$ carbohydrates, $\sim 30 \%$ fat, and $\sim 20 \%$ proteins. Fat reduction is primarily achieved by restriction of animal fat leading to saturated fatty acids contributing less than $7 \%$ to the daily energetic supply. A high proportion of dietary fibers and complex carbohydrates ensure a prolonged feeling of satiety. The weight reduction diet patients continued their diet throughout the entire inpatient stay.

Both treatments were carried out in the context of inpatient naturopathic complex treatment. The mean duration of inpatient naturopathic complex treatment was $19.9 \pm 1.9$ days for all study participants.

The characteristics of the study participants as well as influences of inpatient naturopathic therapy were analyzed using the patient records and a standardized telephone interview. The questions explored the appraisal of fasting therapy, respectively, weight reduction diet, the development of body weight, diet, physical activity, and the influence on the quality of life as well as personal questions. Details and design of the questions, which were sent before the interview by mail to the patients, are displayed in "Supplementary Material" (see Supplementary Material available online at http://dx.doi.org/10.1155/2014/453407). These questions were then asked in the phone interview. The question set for the weight reduction diet patients was the same, with the replacement of "Heilfasten" by "Reduktionsdiät."

The Ethics Committee of the Ruhr University Bochum approved the study (registration number 2976, May 16, 2007), which was undertaken according to the ethical principles of the Declaration of Helsinki.
TABLE 1: Reasons for exclusion from the phone interview.

\begin{tabular}{lcc}
\hline & $\begin{array}{c}\text { Fasting } \\
\text { patients }\end{array}$ & $\begin{array}{c}\text { Weight } \\
\text { reduction } \\
\text { diet patients }\end{array}$ \\
\hline $\begin{array}{l}\text { No longer valid phone number and no } \\
\text { entry in a public phone book }\end{array}$ & $19(24 \%)$ & $6(21 \%)$ \\
$\begin{array}{l}\text { Not reached } \\
\text { Refused to participate }\end{array}$ & $6(8 \%)$ & $2(7 \%)$ \\
$\begin{array}{l}\text { Unable to remember the situations in } \\
\text { question sufficiently }\end{array}$ & $5(6 \%)$ & $2(7 \%)$ \\
$\begin{array}{l}\text { Insufficient German language skills } \\
\text { Participation in other organized weight }\end{array}$ & $2(3 \%)$ & $1(4 \%)$ \\
reduction programs in the meantime & $19(24 \%)$ & $3(11 \%)$ \\
$\begin{array}{l}\text { Malignant disease } \\
\text { Already dead }\end{array}$ & $5(6 \%)$ & $2(7 \%)$ \\
$\begin{array}{l}\text { Bedridden } \\
\text { Undergone intestinal resection }\end{array}$ & $4(5 \%)$ & $5(18 \%)$ \\
$\begin{array}{l}\text { Hospitalization because of an acute } \\
\text { stroke at the time of the telephone }\end{array}$ & $1(1 \%)$ & 0 \\
interview & $1(1 \%)$ & 0 \\
$\begin{array}{l}\text { Moved abroad } \\
\text { Development of dementia }\end{array}$ & 0 & $1(4 \%)$ \\
\hline
\end{tabular}

All patients were sent written information about the study, the planned phone interview, and the voluntariness of participation. They gave oral consent at the beginning of the phone interview.

Patients aged 20 to 70 years who had undergone from 1999 to 2002 as part of the inpatient naturopathic complex treatment at the Blankenstein Clinic, Hattingen, a fasting therapy or a treatment with a weight reduction diet and were overweight (BMI $\left.\geq 25 \mathrm{~kg} / \mathrm{m}^{2}\right)$ or obese $\left(B M I \geq 30 \mathrm{~kg} / \mathrm{m}^{2}\right)$ at this time were included.

Excluded from the study were all patients who had at the time of inpatient therapy one of the following diagnoses: hepatic or renal failure, decompensated hyper- or hypothyroidism, diabetes mellitus type 1, malignant tumors, Crohn's disease or ulcerative colitis, dementia, eating disorders such as anorexia nervosa, bulimia, or binge eating disorder, drug addiction, or serious psychiatric disorders. Also excluded were pregnant or breast feeding women and patients taking medications for overweight and obesity and patients after bariatric therapy.

The record search identified 728 fasting patients and 252 patients who had received a weight reduction diet. 367 of the fasting patients $(50.4 \%)$ and 75 patients with weight reduction diet $(29.8 \%)$ met the inclusion and exclusion criteria. Of the 367 fasting patients a random sample of 200 patients generated using the statistical program SPSS and all 75 patients with weight reduction diet were selected for the telephone interview.

At the time of the telephone interview the exclusion criteria were retrieved and reapplied. The reasons for the subsequent exclusion of 78 fasting and 28 weight reduction diet patients are shown in Table 1. 


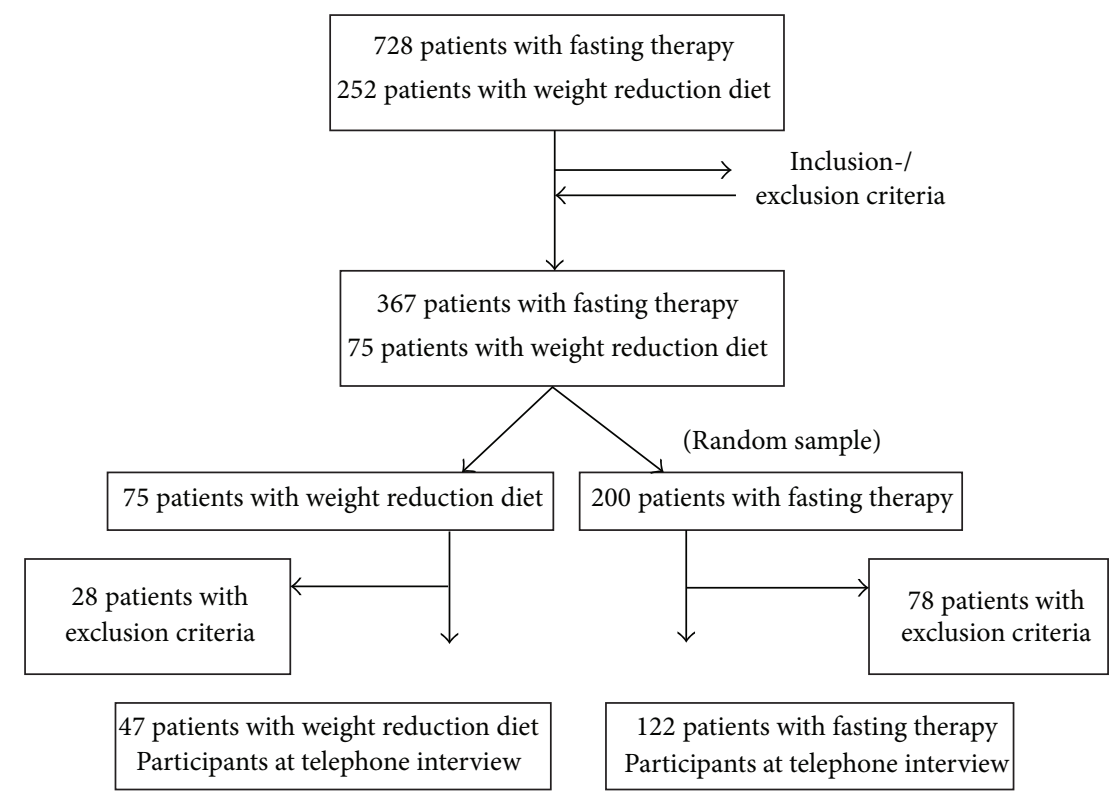

FIGURE 1: Recruitment of study participants.

122 of the 200 fasting patients (61\%) and 47 of the 75 weight reduction diet patients $(62.7 \%)$ ultimately participated in the phone interview. The phone interview was performed on average $6.8 \pm 1.1$ (standard deviation) years after the inpatient therapy (see Figure 1). The mean age of the fasting patients was $55.7 \pm 7.4$ years on admission and $54.5 \pm 10.9$ years for the weight reduction diet patients.

Demographic and biometric characteristics of the patients in the study are shown in Table 2.

Statistical analysis was performed using the computer program "SPSS 17.0 for Windows." Arithmetic mean, standard deviations, medians, and absolute frequencies and percentages were calculated. The presence of normal distribution of metric data was checked using the Kolmogorov-Smirnov test. Statistical tests for parametric data were performed using Student's $t$-test and the Mann-Whitney $U$-test. For nominal and ordinal data Pearson's chi-square test and Fisher's exact test were applied. If the significance level $(P)$ is less than the significance level $\alpha=0.05$, the result is called statistically significant. If it is less than the significance level $\alpha=0.01$, the result is called statistically highly significant [18]. Statistical tests were performed two-tailed in all cases.

Additional descriptive ANCOVAs were performed for BMI and weight with the posttreatment, respectively, actual variable as dependent variable, the group as fixed factors, and pretreatment score and other meaningful and influencing variables as covariates.

As part of the literature review searches in MEDLINE using PubMed and in the databases AMED, EMBASE, CCMed, and CAMbase with the help of the DIMDI were performed because most scientific literature regarding naturopathy is included in these databases. Additionally the Internet search engines Google, Altavista, and Metager were used.
TABle 2: Demographic and biometric characteristics of the study patients.

\begin{tabular}{|c|c|c|}
\hline & $\begin{array}{l}\text { Fasting } \\
\text { patients }\end{array}$ & $\begin{array}{c}\text { Weight } \\
\text { reduction diet } \\
\text { patients }\end{array}$ \\
\hline \multicolumn{3}{|l|}{ Living situation } \\
\hline Living in partnership & $66 \%$ & $66 \%$ \\
\hline Single & $25 \%$ & $21 \%$ \\
\hline $\begin{array}{l}\text { Living in partnership with } \\
\text { children }\end{array}$ & $8 \%$ & $9 \%$ \\
\hline Living with children alone & $1 \%$ & $4 \%$ \\
\hline \multicolumn{3}{|l|}{ Highest graduation } \\
\hline Elementary school & $69 \%$ & $74 \%$ \\
\hline Secondary school & $21 \%$ & $13 \%$ \\
\hline $\begin{array}{l}\text { University-entrance } \\
\text { diploma }\end{array}$ & $10 \%$ & $13 \%$ \\
\hline \multicolumn{3}{|l|}{ Working status } \\
\hline Employed & $21 \%$ & $28 \%$ \\
\hline Housewives/unemployed & $12 \%$ & $6 \%$ \\
\hline Pensioner & $67 \%$ & $66 \%$ \\
\hline \multicolumn{3}{|l|}{ Gender } \\
\hline Female & $84 \%$ & $77 \%$ \\
\hline Male & $16 \%$ & $23 \%$ \\
\hline BMI & $30.8 \pm 4.6 \mathrm{~kg} / \mathrm{m}^{2}$ & $31.6 \pm 4.7 \mathrm{~kg} / \mathrm{m}^{2}$ \\
\hline
\end{tabular}

\section{Results}

The fasting patients reduced their body weight from $86.0 \pm$ $14.1 \mathrm{~kg}$ on admission to $80.1 \pm 13.2 \mathrm{~kg}$ at the end of the fasting 


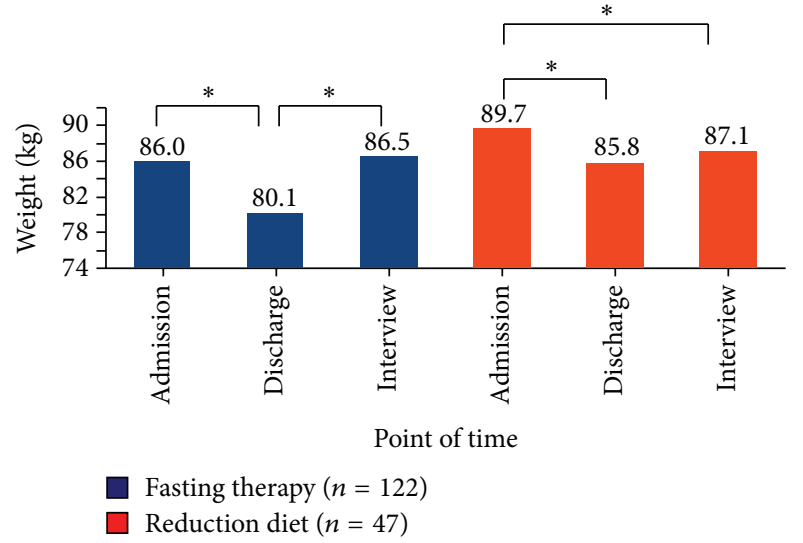

FIGURE 2: Mean of body weight $(\mathrm{kg})$ at the beginning of inpatient treatment, end of treatment, and at telephone interview. * Significant difference within the treatment groups.

therapy. This is a statistically highly significant weight loss during the inpatient fasting therapy $(P<0.001)$.

At the telephone interview the average weight of the patients was $86.5 \pm 15.6 \mathrm{~kg}$ and was thus $0.5 \mathrm{~kg}$ above the mean initial weight on inpatient admission. While the weight regain between the completion of fasting therapy and the telephone interview of the fasting patients was statistically highly significant $(P<0.001)$, there was no difference between the initial weight and the weight at the phone interview $(P=0.349)$.

The weight reduction diet patients reduced their body weight during the inpatient treatment from $89.7 \pm 14.3 \mathrm{~kg}$ to $85.8 \pm 13.5 \mathrm{~kg}$ at the end of the therapy. Again the weight reduction between admission and the end of treatment $(P<$ 0.001 ) is statistically highly significant. The average rebound of the weight up to the telephone interview was $87.1 \pm 16.8 \mathrm{~kg}$, making it an average of $2.6 \mathrm{~kg}$ below the initial weight and $1.4 \mathrm{~kg}$ above the weight at the end of the therapy. The mean body weight at the time of the interview differed statistically significantly from baseline body weight $(P=0.029)$, but not significantly from the weight at the end of the inpatient treatment $(P=0.232)$ (Figure 2).

During inpatient therapy the fasting patients reduced on average significantly more body weight than the weight reduction diet patients $(-5.9 \pm 1.9 \mathrm{~kg}$ versus $-3.9 \pm 1.7 \mathrm{~kg}$, $P<0.001)$ but increased significant more weight again up to the interview $(+6.4 \pm 6.3 \mathrm{~kg}$ versus $+1.4 \pm 7.7 \mathrm{~kg}, P<0.001)$. Overall $10.7 \%$ of the fasting patients and $31.9 \%$ of the weight reduction diet patients lost at least $5 \%$ of their initial weight $(P<0.001)$, the difference being a small to medium statistical effect $(w=0.26)$. On the whole a significantly greater proportion of the weight reduction diet patients $(47 \%)$ than of the fasting patients $(12 \%)$ continued the weight reduction after inpatient treatment until the time of the interview (see Figure 3).

Considering besides the $5 \%$ threshold an absolute weight reduction of more than $2.25 \mathrm{~kg}$ from baseline body weight as a successful weight loss, $26.2 \%$ of the fasting and $55.3 \%$ of the weight reduction diet patients fulfilled this criterion, which

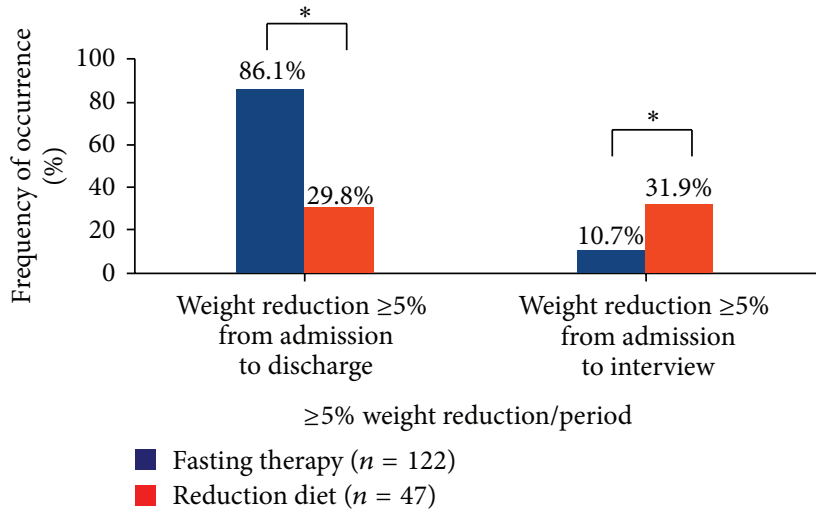

FIGURE 3: Frequency of weight reduction $\geq 5 \%$ of initial weight at the end of inpatient treatment, respectively, at the telephone interview. ${ }^{*}$ Significant differences between the groups $(P<0.001)$.

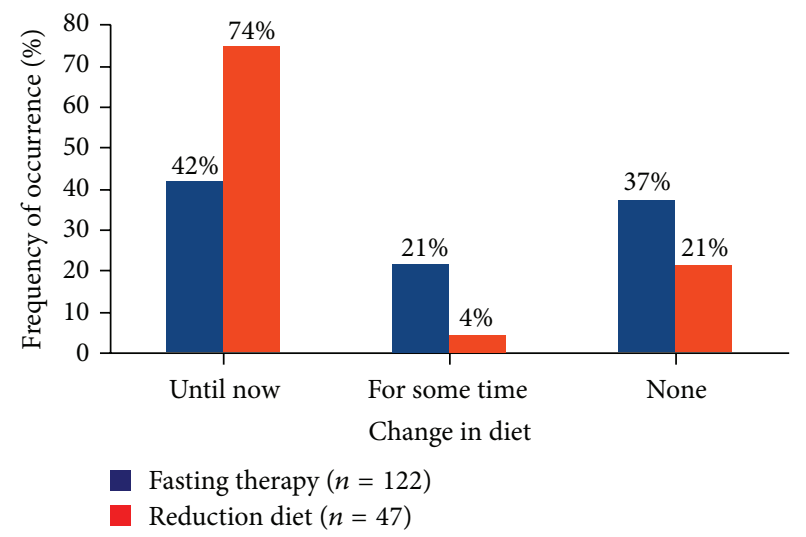

FIGURE 4: Frequency of dietary changes after inpatient therapy. Significant difference between the groups $(P<0.001)$.

is a statistically highly significant $(P<0.001)$ difference between the groups with a small to medium statistical effect $(w=0.28)$.

Looking at the postdischarge dietary changes to a healthy diet according to the requirements of nutrition therapy after discharge from hospital, a clear and statistically highly significant difference between the groups was found $(P<$ $0.001)$. About three quarters of the weight reduction diet patients (74\%) and less than half of the fasting patients (42\%) changed their nutrition after the inpatient therapy "up to this day," that is, up to the time of the interview (see Figure 4).

Of these participants the weight reduction diet patients followed a significantly higher number of inpatient trained nutritional aspects $(P=0.001)$. Thus $77 \%$ of the weight reduction diet patients versus $55 \%$ of the fasting patients stated to consume meat, sausages, and fish at most two to three times per week $(P=0.042) .97 \%$ of weight reduction diet patients versus $75 \%$ of fasting patients preferred lowfat foods $(P=0.006)$. Furthermore, $89 \%$ of the weight reduction diet patients and $68 \%$ of the fasting patients indicated preferring vegetable fats $(P=0.023)$. Finally, $71 \%$ of the weight reduction diet patients and $45 \%$ of the fasting 


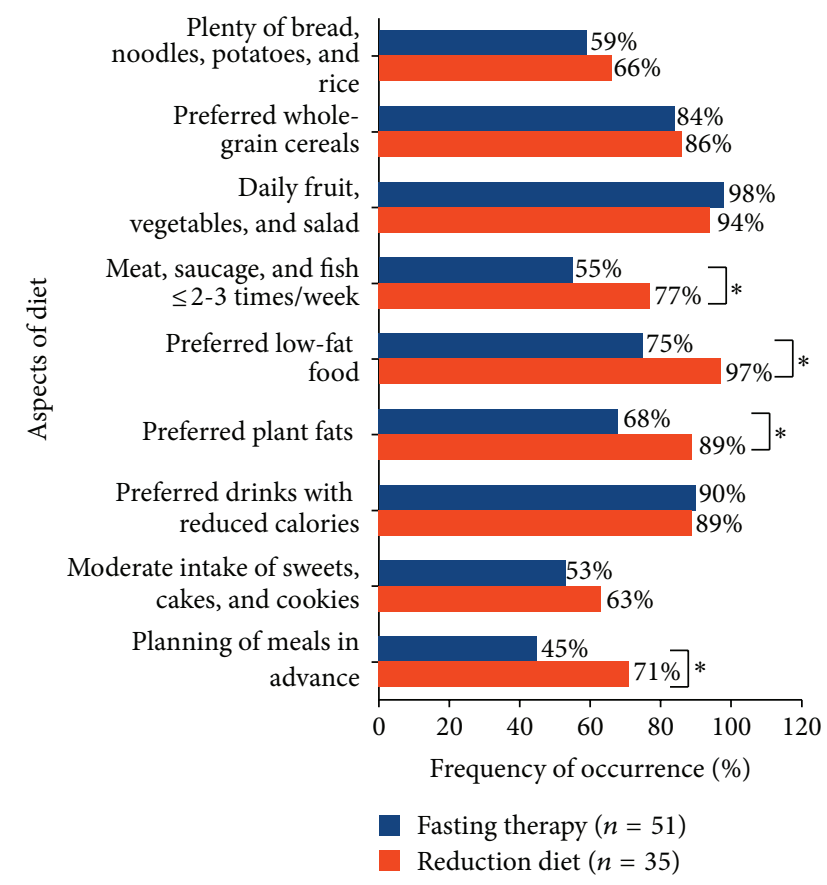

FIGURE 5: Frequency of taught dietary aspects, which study participants observed who changed diet after inpatient therapy. * Significant differences between the groups.

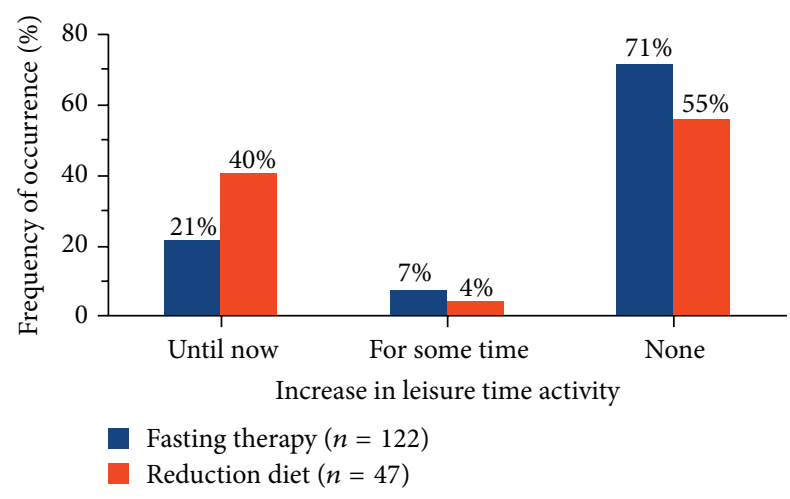

FIGURE 6: Frequency of increased leisure time activity after inpatient therapy. Significant difference between the groups $(P=0.041)$.

patients planned their meals at least a week in advance $(P=$ 0.026) (Figure 5).

While the base and the sports activity was increased in both groups poststationary at similar rates $(P=0.707$ and $P=0.336)$, the increase of leisure time activity was significantly different between the groups $(P=0.041) .21 \%$ of the fasting and $40 \%$ of the weight reduction diet patients increased their leisure activity persistently (Figure 6).

The sustained improvement of quality of life in relation to body weight also showed a significant difference $(P=0.008)$ between the groups. $16 \%$ of the fasting and $28 \%$ of the weight reduction diet patients experienced a sustained improvement in quality of life in this regard (Figure 7).

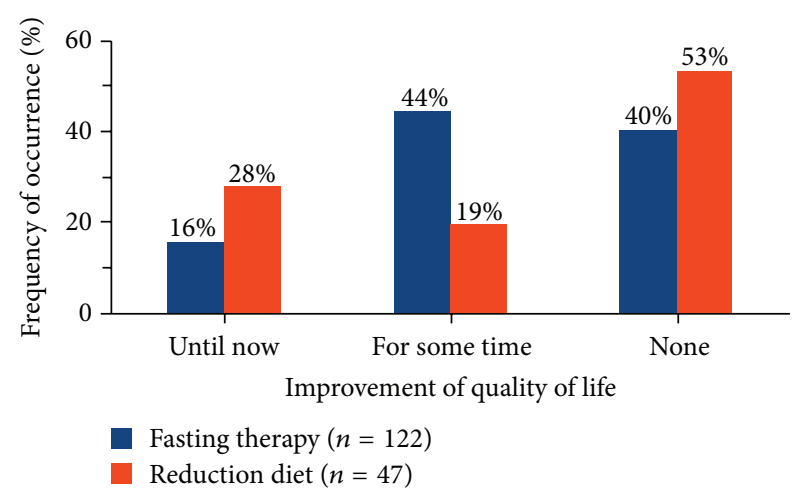

FIGURE 7: Frequency of improvement of quality of life regarding body weight after inpatient therapy. Significant difference between the groups $(P=0.008)$.

Additional descriptive ANCOVA for BMI, respectively, weight with the actual measurement as dependent variable and the treatment group as fixed factor shows significant results for all covariates pretreatment score $(P<0.001)$, negative concomitant conditions (sum of "yes"-answers to "no support by family/social contacts," "stressful everyday life," "immobility due to disease," "medication impairing weight loss," "eating because of chronic pain," "dramatic biographical events like death of a family member," "stopping smoking," "healthy food not tasty," "difficulties to reduce eating candies and cakes", and "other factors"; $P=0.002$, resp., $P=0.005$ ), physical activity (sum of increased everyday life activity, estimated with half an hour per day, leisure time activity, time used for sports, time used for gardening, time used for walking and biking, time for ascending stairs, 2 minutes per floor; $P=0.003$, resp., $P=0.014$ ), and number of taught nutritional aspects applied in everyday life $(P<0.001)$. Only the test between the treatment groups is not significantly different in this ANCOVA $(P=0.440$, resp., $P=0.692)$. If the covariate "number of taught nutritional aspects applied in everyday life" is omitted, the test between the treatment groups in the ANCOVA turns to significance $(P=0.003$, resp., $P=0.010$ ) showing that the difference between the treatment groups concerning this factor is mainly responsible for the different success rates in the treatment groups.

Descriptive ANCOVAs for BMI and weight with the measurement after treatment at discharge from hospital as dependent variable and the treatment group as fixed factor show significant (for weight and negative concomitant conditions only tendential) results for the covariates pretreatment score $(P<0.001)$ and negative concomitant conditions $(P=$ 0.031 , resp., $P=0.060)$ and the test between the treatment groups $(P<0.001)$.

ANCOVAs with additional covariates as age, age at manifestation of adipositas, duration of adipositas in years, adipositas of family members, and number of educational teaching sessions show no additional significant factors (the significance of the covariates described above is partly lost when adding too many other covariates in the model). 


\section{Discussion}

A sustained weight loss of $5 \%$ of the initial weight is the primary goal of therapy according to the guideline for the treatment and prevention of obesity [6], because this is considered to be an achievable goal and also implicates health benefits. In this study, $10.7 \%$ of the fasting and $31.9 \%$ of the weight reduction diet patients reached this goal. While participants after weight reduction diet had good long-term results compared to current literature, the fasting patients reached on average their initial weight again after an initial weight loss. The small to medium statistical effect with respect to the difference between fasting and weight reduction diet patients appears to be clinically relevant against the background of low long-term success rates in the treatment of obesity. Furthermore, the fasting patients achieved unlike the weight reduction diet patients no lasting weight reduction of at least $2.25 \mathrm{~kg}$ of the starting weight, which would be beneficial for health. The reduction of cardiovascular risk factors and an increase in health and well-being have been demonstrated in various studies [19] for a permanent weight loss of $2.25 \mathrm{~kg}$. One likely determinant of the less successful long-term weight loss of fasting patients constitutes the lesser lifestyle modification in this group.

Regarding the development of the weight after discharge from hospital only $12 \%$ of fasting patients compared with nearly $47 \%$ of weight reduction diet patients were able to continue the reduction of body weight after the end of inpatient treatment. In addition $14 \%$ of fasting patients and $49 \%$ of weight reduction diet patients gained persistent weight stabilization. One possible explanation for this comparatively high proportion of fasting patients who could not stabilize their weight after discharge from hospital is that fasting lowers plasma glucose levels which on the other hand may result in subsequent weight regain [20].

In both groups most study participants who could not stabilize their body weight increased their weight again within the first 4-12 months after the inpatient treatment. In the context of current literature on the treatment of obesity a weight regain after about 5 months turns out to be a typical phenomenon [21].

Finally $42 \%$ of fasting patients and $74 \%$ of weight reduction diet patients changed their diet after discharge from hospital up to the time of the telephone interview according to the rules of nutrition learned during the inpatient therapy (Figure 4). A prevailing proportion of patients with successful weight reduction could only be detected in the group of study participants who had changed their nutrition for the whole observation period.

But this study showed not only differences between fasting and weight reduction diet with respect to the proportions of patients who switched their diet, but also detailed changes in nutrition (Figure 5). While study participants following up to five aspects of nutrition did not achieve weight loss (median), study participants following eight aspects of nutrition reduced their weight (median) for $4.7 \mathrm{~kg}$ and study participants following nine aspects lost minus $13.0 \mathrm{~kg}$ body weight (median). With respect to individual aspects of nutrition the weight reduction diet patients ate significantly less meat, sausage, and fish compared to the fasting patients and preferred significantly more low-fat foods and vegetable fats. Thus, weight reduction diet patients reduced the amount of dietary fat significantly more than the fasting patients. This may partly be due to a lower consumption of meat and sausage. The National Nutrition Survey in Germany in 2008 showed that the majority of recorded dietary fat is caused by the consumption of meat and sausage [22]. Moreover, the weight reduction diet patients significantly more often planned their meals in advance for the following week. The planning of meals can be understood as a kind of cognitive control of eating habits [5] and proved in literature as an effective strategy for long-term successful weight loss [23].

One possible explanation for the fact that the fasting patients changed their nutrition less frequent compared to the weight reduction diet patients and adhered seldom to learned nutritional aspects and to a lower-fat diet may be found by analysis of therapeutic approaches. While the weight reduction diet patients used the learned theoretical nutritional aspects practically during the whole inpatient therapy, the fasting patients collected after the passive state of food abstinence only few and short practical experience (3-4 days) of the possible modifications to their diet.

With regard to this possible explanation, a review that compares different approaches to the treatment of obesity shows that participants of study arms in 28 included studies that exclusively obtained a theoretical guidance for diet had similar results of long-term weight reduction as the fasting patients in the present study. A long-term weight loss over several years could not be reached by theoretical instruction [24].

The assumed potential of fasting therapy for long-term changes in diet [25] was not confirmed by the present study. The fasting therapy carried out as part of the inpatient naturopathic complex treatment in this patient population proved to be less suitable compared to standard therapy for the treatment of overweight and obesity.

Both the fasting and the weight reduction diet patients who increased their sports activity permanently showed no greater weight loss than those participants who did not or only for a short period increase their sports activity. A possible explanation is the lower energy costs for the sports activities compared to the increase in base and leisure activity. The sports activities were increased only for 2.0 hours per week (median) and most often in the form of gymnastics, a sport activity with comparable low energetic intensity. Levine showed in his review that people who reported to be physically active spent mostly no more than 2 hours per week for this and that this accounts only for an additional energy expenditure of $100 \mathrm{kcal}$ per day [26]. However, this author showed also that a regular increase of the daily everyday life and leisure activity leads to a significantly higher energy expenditure and plays thus a crucial role in the regulation of overweight and obesity [26]. Therefore, the significant increase of base and leisure activity in weight reduction diet patients compared to fasting patients is another possible explanation for the successful long-term weight loss of weight reduction diet patients. 
$16 \%$ of the fasting and $28 \%$ of the weight reduction diet patients experienced a continued improvement in quality of life after discharge from hospital. Almost half of the fasting patients (44\%) and 19\% of the weight reduction patients stated that quality of life has improved in this regard only for a period (Figure 7). This period lasted for 10.0 months (median) in the group of fasting patients and for 11.0 months (median) in the group of weight reduction diet patients.

With respect to the $2.25 \mathrm{~kg}$ weight loss criterion according to Williams et al. [19] about half of the patients (approximately $59 \%$ of fasting patients and almost $50 \%$ of weight reduction diet patients) in this study, who could stabilize permanently a weight reduction of at least $2.25 \mathrm{~kg}$, also specified a lasting improvement in the quality of life with regard to body weight.

While in the present study fasting and weight reduction diet patients considered their weight-related quality of life during the inpatient treatment equally, at the time of the telephone interview the weight reduction diet patients were significantly less affected $(P=0.033)$.

Thus even a relatively small reduction in weight may influence considerably the quality of life.

Fasting patients benefited less than weight reduction diet patients in terms of long-term weight loss as well as in terms of weight-related quality of life.

\section{Conclusions}

Fasting therapy in the context of inpatient naturopathic complex treatment is less suitable for the treatment of overweight and obesity than low-calorie diet. Fasting therapy followed by long-term supervised weight reduction diet and fasting therapy for the prevention of obesity remains to be evaluated in the future.

\section{Conflict of Interests}

The authors declare that there is no conflict of interests regarding the publication of this paper.

\section{References}

[1] R. H. Eckel and R. M. Krauss, "American Heart Association call to action: obesity as a major risk factor for coronary heart disease," Circulation, vol. 97, no. 21, pp. 2099-2100, 1998.

[2] H. Gohlke, C. Albus, G. Bönner et al., "Leitlinie Risikoadjustierte Prävention von Herz-und Kreislauferkrankungen,” 2007, http://leitlinien.dgk.org/images/pdf/leitlinien_volltext/200710_Risikoadjustierte.pdf.

[3] D. F. Williamson, T. J. Thompson, M. Thun, D. Flanders, E. Pamuk, and T. Byers, "Intentional weight loss and mortality among overweight individuals with diabetes," Diabetes Care, vol. 23, no. 10, pp. 1499-1504, 2000.

[4] E. E. Calle, C. Rodriguez, K. Walker-Thurmond, and M. J. Thun, "Overweight, obesity, and mortality from cancer in a prospectively studied cohort of U.S. Adults," The New England Journal of Medicine, vol. 348, no. 17, pp. 1625-1638, 2003.

[5] T. Ellrott and V. Pudel, Adipositastherapie. Aktuelle Perspektiven, Georg Thieme, Stuttgart, Germany, 1998.
[6] A. Berg, S. C. Bischoff, M. Colombo-Benkmann et al., Interdisziplinäre Leitlinie der Qualität S3 zur "Prävention und Therapie der Adipositas" Version 2.0, 2014, http://www .adipositas-gesellschaft.de/fileadmin/PDF/Leitlinien/S3_Adipositas_Praevention_Therapie_2014.pdf.

[7] R. Kluthe, A. Dittrich, R. Everding et al., "Das Rationalisierungsschema 2004 des Bundesverbandes Deutscher Ernährungsmediziner (BDEM) e. V., der Deutschen Adipositas Gesellschaft e. V., der Deutschen Akademie für Ernährungsmedizin (DAEM) e. V., der Deutschen Gesellschaft für Ernährung (DGE) e. V., der Deutschen Gesellschaft für Ernährungsmedizin (DGEM) e. V., des Verbandes der Diätassistenten-Deutscher Bundesverband (VDD) e. V. und des Verbandes der Diplom-Oecotrophologen (VDO E ) e. V., Aktuel Ernahrungsmed, vol. 29, no. 5, pp. 245-253, 2004.

[8] A. Michalsen, B. Hoffmann, S. Moebus, M. Bäcker, J. Langhorst, and G. J. Dobos, "Incorporation of fasting therapy in an integrative medicine ward: evaluation of outcome, safety, and effects on lifestyle adherence in a large prospective cohort study," Journal of Alternative and Complementary Medicine, vol. 11, no. 4, pp. 601-607, 2005.

[9] T. Pötschke and B. Weidner, "Ernährungstherapie," in Leitfaden Naturheilverfahren für die Ärztliche Praxis, A. M. Beer and M. Adler, Eds., Urban \& Fischer, Munich, Germany, 2012.

[10] H. Fahrner, Fasten als Therapie. Physiologie und Pathophysiologie, Methodik, Indikationen und Verläufe, Psychologische Aspekte, Hippokrates, Stuttgart, Germany, 1991.

[11] F. Wilhelmi de Toledo, A. Buchinger, H. Burggrabe et al., "Leitlinien zur Fastentherapie," Forsch Komplementarmed Klass Naturheilkd, vol. 9, no. 3, pp. 189-198, 2002.

[12] A. M. Johnstone, "Fasting-the ultimate diet?" Obesity Reviews, vol. 8, no. 3, pp. 211-222, 2007.

[13] H. Müller, P. Schuck, and K. L. Resch, "Pharmakologische bewertung von adipositas-therapeutika: kaum forschung zum heilfasten," Deutsches Ärzteblatt, vol. 97, no. 22, p. A-1542, 2000.

[14] A. Michalsen, W. Weidenhammer, D. Melchart, J. Langhorst, J. Saha, and G. Dobos, "Short-term therapeutic fasting in the treatment of chronic pain and fatigue syndromeswell-being and side effects with and without mineral supplements," Forschende Komplementärmedizin und klassische Naturheilkunde, vol. 9, no. 4, pp. 221-227, 2002.

[15] E. Peper, J. Rogner, and H. Hettwer, "Stationäres Heilfasten. Prä-/Post-Befragung zum körperlichen und emotionalen Befinden sowie erlebten Veränderungen," Prävention und Rehabilitation, vol. 8, no. 3, pp. 129-136, 1996.

[16] J. M. Schmidt and B. Ostermayer, Die Heilfasten-Basisdokumentation am Krankenhaus für Naturheilweisen (19951999), Krankenhaus für Naturheilweisen, München, Germany, 1995.

[17] H. Anemueller, Naturheilverfahren-Ernährungstherapie. Vollwertige Grunddiät mit Ableitungen, Hippokrates, Stuttgart, Germany, 1998.

[18] J. Bortz, Statistik für Human-und Sozialwissenschaftler, Springer, Heidelberg, Germany, 2005.

[19] L. T. Williams, A. F. Young, and W. J. Brown, "Weight gained in two years by a population of mid-aged women: how much is too much?" International Journal of Obesity, vol. 30, no. 8, pp. 1229-1233, 2006.

[20] N. G. Boulé, J.-P. Chaput, E. Doucet et al., "Glucose homeostasis predicts weight gain: prospective and clinical evidence," Diabetes/Metabolism Research and Reviews, vol. 24, no. 2, pp. 123129, 2008. 
[21] C. G. Ulen, M. M. Huizinga, B. Beech, and T. A. Elasy, "Weight regain prevention," Clinical Diabetes, vol. 26, no. 3, pp. 100-113, 2008.

[22] Max Rubner-Institut and Bundesforschungsinstitut für Ernährung und Lebensmittel, "Nationale Verzehrsstudie II. Ergebnisbericht Teil 2. Die bundesweite Befragung zur Ernährung von Jugendlichen und Erwachsenen," 2008, http:// www.bmelv.de/SharedDocs/Downloads/Ernaehrung/NVS ErgebnisberichtTeil2.pdf?__blob=publicationFile.

[23] J. Kruger, H. M. Blanck, and C. Gillespie, "Dietary and physical activity behaviors among adults successful at weight loss maintenance," International Journal of Behavioral Nutrition and Physical Activity, vol. 3, article 17, 2006.

[24] M. J. Franz, J. J. VanWormer, A. L. Crain et al., "Weight-loss outcomes: a systematic review and meta-analysis of weight-loss clinical trials with a minimum 1-year follow-up," Journal of the American Dietetic Association, vol. 107, no. 10, pp. 1755-1767, 2007.

[25] F. W. deToledo, R. Friebe, D. Hebisch, C. Kuhn, G. Platzer, and S. Schrag, "The Buchinger Klinik Program for the treatment of obesity," in Obesity in Europe 1993, pp. 289-293, 1994.

[26] J. A. Levine, "Nonexercise activity thermogenesis-liberating the life-force," Journal of Internal Medicine, vol. 262, no. 3, pp. 273-287, 2007. 


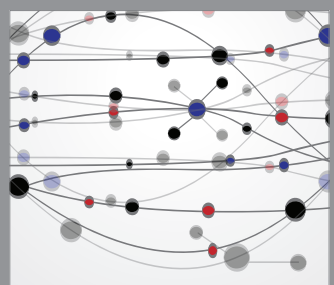

The Scientific World Journal
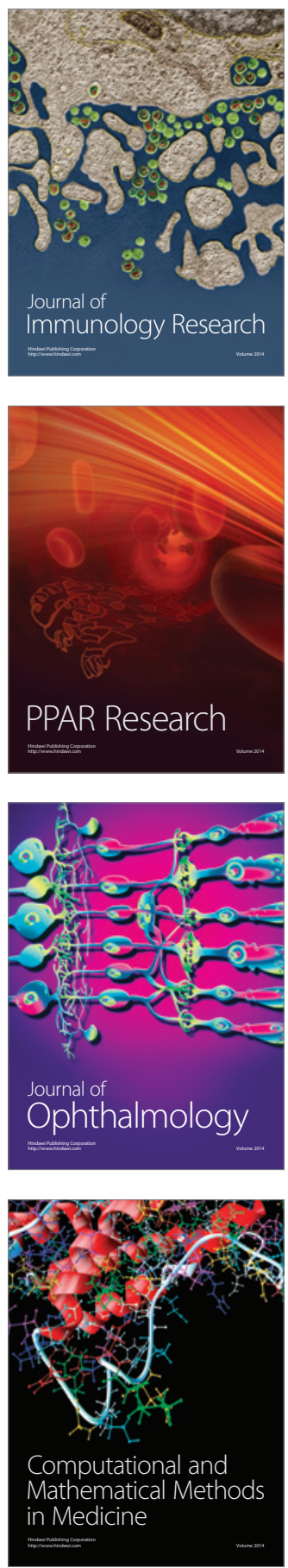

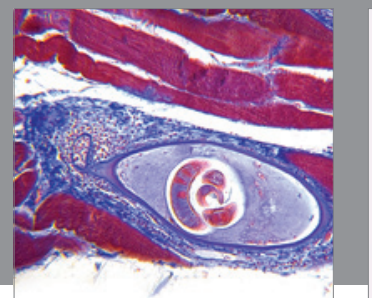

Gastroenterology

Research and Practice
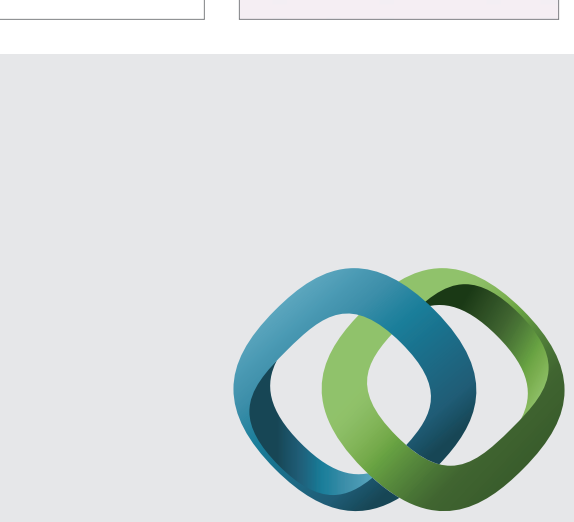

\section{Hindawi}

Submit your manuscripts at

http://www.hindawi.com
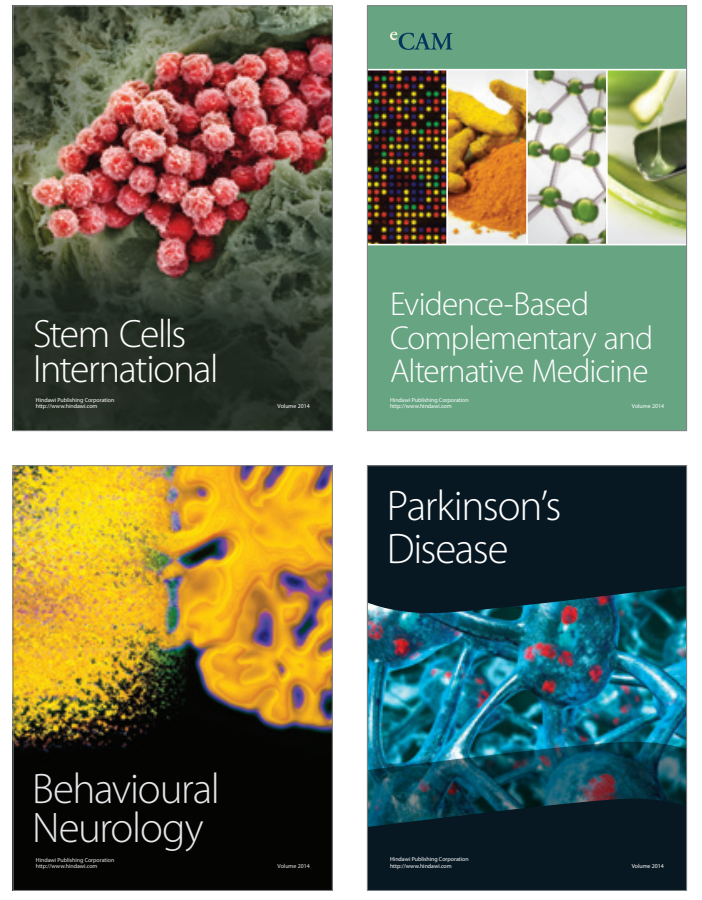
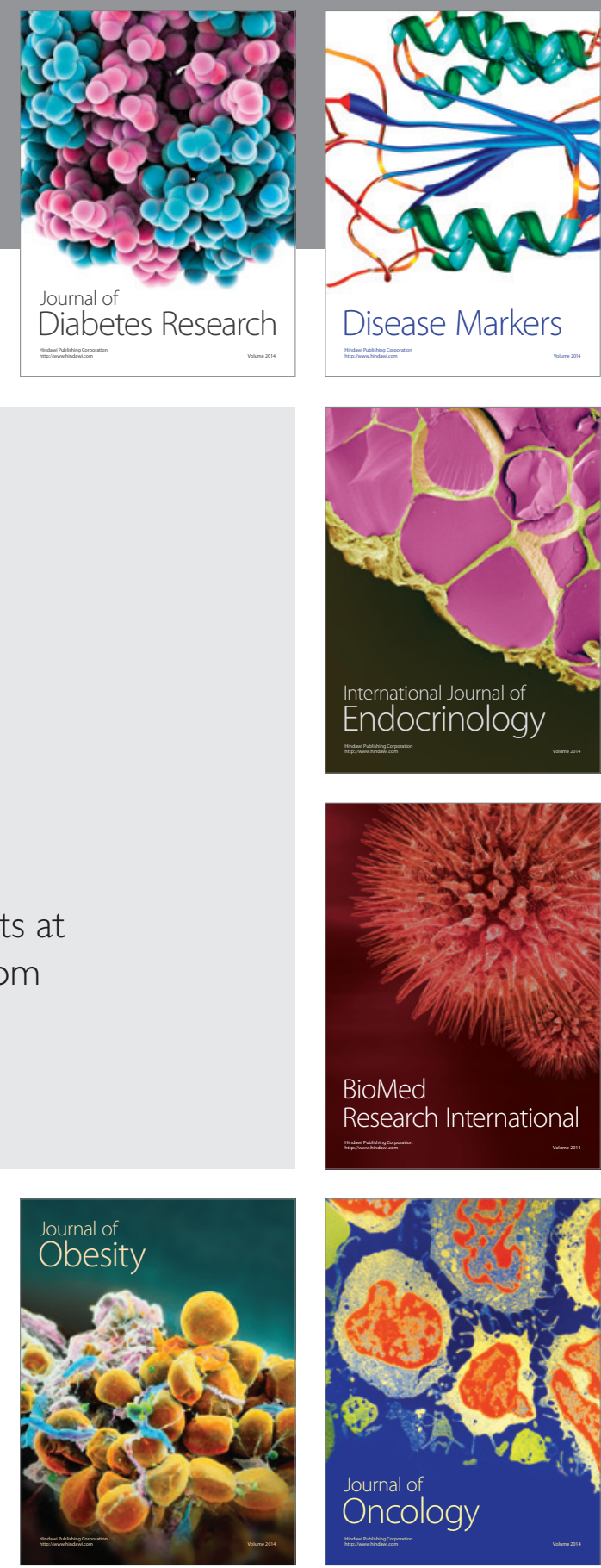

Disease Markers
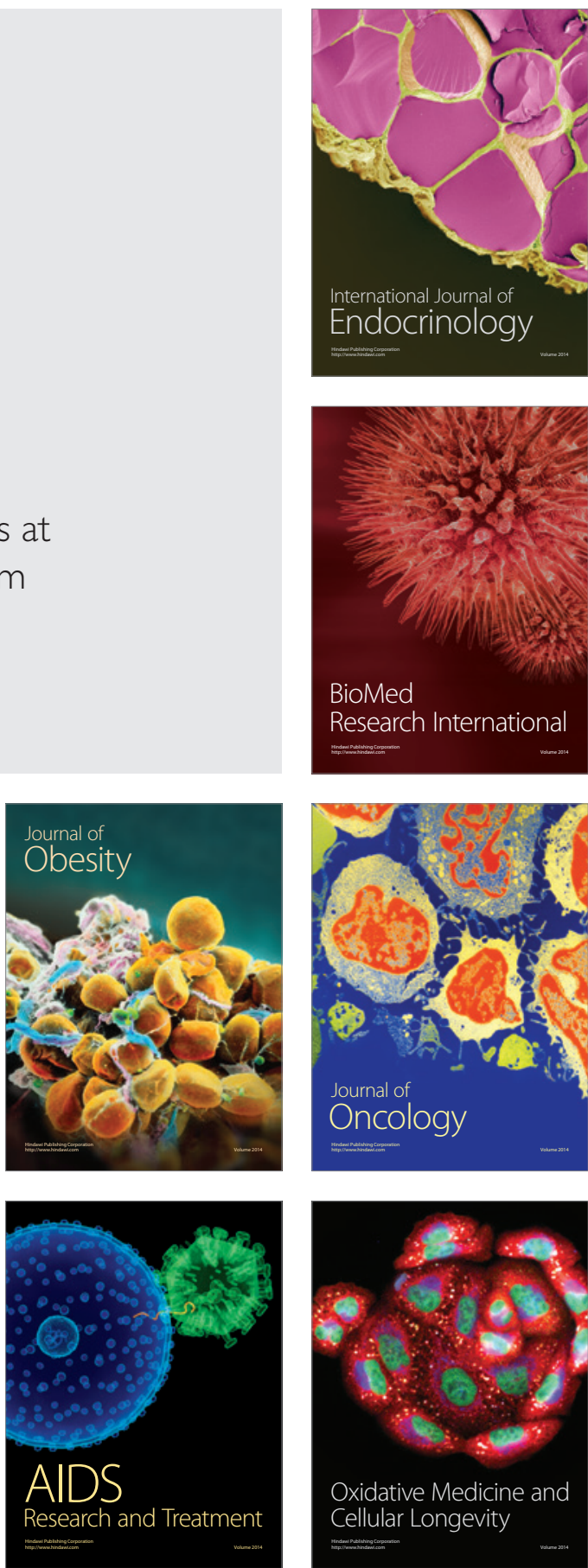